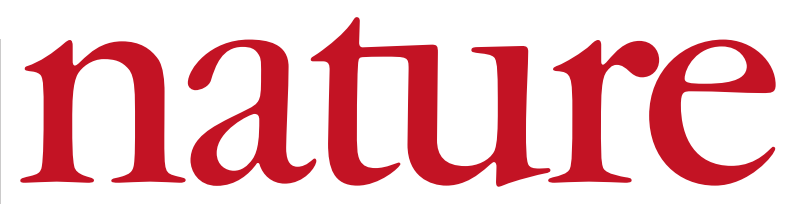

27 May 2004 Volume 429 Issue no 6990

\title{
The rise of café culture
}

A night out in a bar is all the more enjoyable if you can digest some science too. That's the lesson of a growing movement whose character may be local but whose reach is potentially global — and at a small cost.

S ince last November, the small English market town of Settle in Yorkshire has added an unusual entry to its social calendar: a regular night of science debate. On a cold evening this February, for example, mathematician David Salinger journeyed from the nearby University of Leeds to discuss the mathematical meaning of infinity - hardly a typical night down the pub.

Salinger is not alone. In cities across Britain and France, academics regularly give up their evenings to join in with these Café Scientifique debates. And as a conference of debate organizers in Newcastle upon Tyne, UK, heard last weekend, similar events are now established in towns in eleven countries, from Buenos Aires to Warsaw to Houston, Texas (see page 333).

Given that the first Café Scientifique was held in 1997, the spread of the events has been remarkable and should be welcomed. Governments across Europe have stressed the need to improve dialogue between scientists and the public. The café organizers, using almost no public money and with little central organization, have created a network of successful events that does just that.

But a little central support could go a long way. The British cafés built a network thanks to a small grant — $£ 175,000$ (US\$315,000) from the Wellcome Trust. The trust only provides money to kickstart such schemes, so another body will be needed to support the activities. This would surely be a worthwhile investment for any organization that cares about science communication.

The organizers also face a lingering distrust of their events from within the professional science-communication community. Sceptics point out that the events attract a mainly middle-class audience, the type of people who already engage with science through museums and the media. A better event, they argue, would reach minority communities who feel excluded from science and, more importantly, from democratic decision-making about scientific issues.

This may be true, but it also misunderstands what the cafés can achieve. The events are run by local people who give their time free of charge. Event organizers know they are reaching a middle-class audience and, by and large, this does not bother them too much. These are not professional events - they are the science equivalent of the book club, run by enthusiasts, for enthusiasts.

Even if organizers were more committed to reaching minority communities, it is questionable whether the debate format is the best vehicle for doing so. Minority communities often ignore the mainstream science events, such as exhibitions and festivals, that already exist. Why should the cafés, developed and run by mainly white, middle-class professionals, be any different?

Inspiration should be drawn instead from programmes that have been created for particular communities. Take, for example, the Dana Centre in London, an offshoot of the Science Museum designed to host debates about science and culture.

Staff there have produced an event about climate change for the city's Bangladeshi population. The issue is relevant to the community, as rising sea levels could devastate their low-lying Asian homeland. Realizing that the community was unlikely to cross London to visit the museum, the centre took its event — an interactive theatre piece - to a local community centre. The result was a spirited debate and a determination by both sides to run more such shows.

\section{Dragged into the fray}

\section{Willingly or not, Russia's science academy has become part of the political economy of climate.}

W e've been here before. Last December, Russian ministers and advisers were sending contradictory signals about whether they would ratify the Kyoto Protocol for climate change, in the end leaving the issue unresolved. Last week saw an apparently similar phenomenon, except that in the process the Russian Academy of Sciences apparently allowed itself to be hijacked by opponents of the protocol.

According to the news agency Reuters, a document handed to Russian President Vladimir Putin by the academy strongly opposed ratification, asserting that the protocol "lacks a scientific basis" and would put a brake on Russia's economic development. This matters, because Russia's ratification would bring the Kyoto Protocol into force.

The report, commissioned by Putin in January, was adopted by an academy commission on 14 May, despite disagreement among leading Russian climate scientists about its tone and recommendations.

Climate researchers are upset that the report's main author, Yuri Izrael, director of the academy's Institute of Global Climate and Ecology in Moscow and an influential scientific adviser to the Kremlin, is also a vice-chairman of the Intergovernmental Panel on Climate
Change (IPCC). As such, he was a signatory to the IPCC's 2001 assessment of climate change - the very document that flatly contradicts some of the Russian anti-Kyoto statements.

There are suggestions that the chairman of the IPCC, Rajendra Pachauri, might take some action against Izrael. This should be resisted, partly because the IPCC has better things to do, and partly because the Russian report may well be part of a political charade. It appeared in the same week as a summit between Russia and the European Union (EU) in which Putin sought approval and improved conditions for entry into the World Trade Organization. The EU is a strong supporter of Kyoto. Lo, Putin got the backing he wanted and, lo again, he immediately expressed his willingness for Russia to move towards ratification of Kyoto.

How and why the academy allowed itself to become a pawn may never be clear to outsiders. What is clear is that science in Russia, as elsewhere, has been hijacked by the politics and economics of energy investment and emission reductions. Anyone seeking to interpret messages about such science should apply the same filter of scepticism as they do to politics. Even so, the bottom line is that prospects for the Kyoto Protocol are brighter than they have been for a while. 